Science 221:1067-1070

17. Quissell DO 1980 Secretory response of dispersed rat submandibular cells: I. Potassium release. Am J Physiol 238:C90-C98

18. Lowry OH, Rosebrough NF, Farrar AL, Randall RJ 1951 Protein measurement with the Folin phenol reagent. J Biol Chem 193:265-268

19. Perlmutter J, Martinez JR 1978 The chornically reserpinized rat as a possible model for cystic fibrosis: VII. Alterations in the secretory response to secretin and to cholecystokinin from the pancreas in vivo. Pediatr Res 12:188-194
20. Mawhinney TP, Feather MS, Martinez JR, Barbero GJ 1979 The chronically reserpinized rat as an animal model for cystic fibrosis: acute effect of isoproterenol and pilocarpine upon pulmonary lavage fluid. Pediatr Res $13: 760-763$

21. Frizzell RA, Fields M, Schultz SG 1979 Sodium-coupled chloride transport by epithelial tissues. Am J Physiol 236:F1-F8

22. Welsh M 1983 Inhibition of chloride secretion by furosemide in canine tracheal epithelium. J Memb Biol 71:219-226

\title{
Defective Regulation of Immune Responses in Croup Due to Parainfluenza Virus
}

\author{
ROBERT C. WELLIVER, MARTHA SUN, AND DEBORAH RINALDO \\ Department of Pediatrics, State University of New York at Buffalo, and Division of Infectious Diseases, \\ Children's Hospital, Buffalo, New York 14222
}

\begin{abstract}
In order to determine if defects in regulation of immune responses play a role in the pathogenesis of croup, we studied 37 infants and children with either croup or upper respiratory illness alone due to parainfluenza virus (PV). PV-specific IgE responses were determined by an enzyme-linked immunosorbent assay, cell-mediated immune responses to $P V$ antigen were studied by in vitro lymphocyte transformation assays, and suppressor cell function was determined by addition of histamine to lymphocyte transformation assays. In comparison to patients with upper respiratory illness alone, patients with croup had increased production of PV-specific IgE antibody, increased lymphoproliferative responses to $\mathrm{PV}$ antigen, and diminished histamine-induced suppression of lymphocyte transformation responses to $P V$. These results suggest that a defect in suppressor function exists among croup patients. Similar defects have been demonstrated in bronchiolitis and atopic diseases, providing an immunologic link between the three illnesses. (Pediatr Res 19: 716-720, 1985)
\end{abstract}

\section{Abbreviations}

URI, Upper respiratory tract infection

PV, Parainfluenza virus

LTF, Lymphocyte transformation

PHA, Phytohemagglutinin

$\triangle \mathrm{cpm}$, Change in counts per minute

NPS, Nasopharyngeal secretions

RSV, respiratory syncytial virus

Received October 29, 1984: accepted March 11, 1985

Correspondence Robert C. Welliver, M.D., Associate Professor of Pediatrics, Division of Infectious Diseases, Children's Hospital, 219 Bryant Street, Buffalo, NY 14222.

Supported by grants from the National Heart, Lung and Blood Institute (HL21829-05), the National Institute of Allergy and Infectious Diseases (AI-15939-01), and the National Institute of Child Health and Human Development (HD-15943$02)$.
Croup is a common respiratory illness of childhood, yet fairly little is known about its pathogenesis. The agents that most commonly cause croup are the parainfluenza viruses (1), yet infection with these agents in most individuals results in minor upper URI alone $(2,3)$. It is conceivable therefore that host factors play a role in the pathogenesis of croup.

It has recently been demonstrated that patients with both croup and wheezing due to PV manifest greater PV-specific IgE antibody production in NPS than patients with URI alone due to PV (4). IgE synthesis in rodents (5) and, presumably, in humans $(6,7)$ is regulated by T-lymphocytes whose suppressive effect on antibody synthesis is specific for the IgE isotype. We undertook the current study with the hope of detecting evidence of a defect in immunosuppression among patients with croup due to PV. In this regard, we studied LTF responses to PV antigen in blood samples obtained from patients with croup and with URI alone due to PV. In addition, we investigated possible differences in histamine-induced suppression of lymphoproliferative responses (8) among patients with croup or URI alone due to PV.

\section{MATERIALS AND METHODS}

Study population and specimen collection. The study group consisted of 37 infants and children ranging in age from 3 months to $7 \mathrm{yr}$ recruited primarily from the acute disease clinic of Children's Hospital at the time of initial presentation with respiratory illness. Parents were advised of the goals and risks of the study, and signed statements of informed consent were obtained. A few patients were either recruited at the time of hospitalization for croup or were followed as part of an ongoing study of respiratory illness in childhood. All patients were studied during the autumn of 1983. Twenty-seven patients were classified as having croup on the basis of the presence of inspiratory stridor and a barking cough. Seventeen of the patients had a history of a previous episode of croup. While the diagnosis of croup was made on a clinical basis, lateral neck radiographs were frequently ordered by house officers as part of routine care of these patients and, when obtained, uniformly were read by radiologists as demonstrating diffuse narrowing of the subglottic area consistent with croup. The median age of croup patient was 14 months 
(range 3 to 48 months). Ten patients had URI alone, based on the presence of rhinorrhea and mild cough without stridor, hoarseness, or wheezing. The median age of the URI group was 18 months (range 1 to 62 months).

At the time of recruitment into the study, samples of NPS were obtained as previously described (4) for documentation of $\mathrm{PV}$ infection and for determination of PV-IgE antibody titer. A small sample of serum was also obtained for serologic studies. Patients were requested to return 4 to 8 wk later when similar samples of NPS and serum were obtained. At the follow-up visit an additional 3.5-ml sample of heparinized blood was obtained for analysis of histamine-induced suppression of LTF responses to PV antigen and mitogen. This assay was not performed at the time of the initial hospital visit, because preliminary studies demonstrated that significant LTF responses to PV were usually not present during the acute illness.

Documentation of PV infection. Infection with PV was documented initially by identification of viral antigen in NPS specimens using indirect immunofluorescence techniques previously described from this laboratory (9) and later confirmed in all cases by $\mathrm{a} \geq 4$-fold rise in serum hemagglutination inhibition antibody to PV, and usually by recovery of PV in tissue culture. The PV type causing infection was determined using the strongest typespecific serologic response as the sole criterion. Approximately $70 \%$ of croup cases and the same percentage of URI episodes were caused by PV type 1 . All other infections were caused by PV type 3.

$P V$-specific IgE antibody determinations. Titers of PV-specific IgE in NPS specimens were determined using an enzyme-linked immunosorbent assay assay previously described in a publication from this laboratory (4). In brief, laboratory-raised stock strains of PV types 1,2, and 3 were allowed to adhere to polyvinyl micro-enzyme-linked immunosorbent assay plates (Dynatech Laboratories, Alexandria, VA) and were overlaid with samples of NPS serially diluted in phosphate-buffered saline. Plates were then incubated first with horseradish peroxidase-conjugated goat anti-human IgE (Miles Laboratories, Elkhardt, IN) and then 5aminosalicyclic acid (Sigma Chemical, St. Louis, MO). Endpoints were read by eye and spectrophotometer at $488 \mathrm{~nm}$. Titers of PV-IgE measured were standardized to a protein content of 1 $\mathrm{mg} / \mathrm{ml}$ of fluid in the original specimen. Titers presented in the "Results" section and in Table 1 and 3 represent the PV-IgE titer against the PV type causing infection.

The specificity of the assay for IgE was indicated by control experiments in which positive reactions could be blocked by preincubation of the goat anti-human $\operatorname{IgE}$ with purified human

Table 1. LTF responses to PV antigen in patients with non-PV infections

\begin{tabular}{clc}
\hline Patient & $\begin{array}{c}\text { Infectious agent } \\
\text { recovered }\end{array}$ & $\begin{array}{c}\text { LTF response to PV antigen } \\
\text { (stimulation index; } \Delta \text { cpm) }\end{array}$ \\
\hline 1 & Adenovirus & $1.0 ; 15$ \\
& RSV & $1.5 ; 82$ \\
& Influenza virus & $1.2 ; 36$ \\
2 & Adenovirus & $1.4 ; 17$ \\
& None & $1.4 ; 63$ \\
& RSV & $1.5 ; 45$ \\
3 & None & $1.0 ; 6$ \\
& Adenovirus & $1.1 ; 27$ \\
& Influenza virus & $1.3 ; 54$ \\
& None & $1.1 ; 90$ \\
& RSV & $1.1 ; 32$ \\
4 & RSV & $1.1 ; 15$ \\
& None & $1.0 ; 2$ \\
& Influenza virus & $1.5 ; 68$ \\
\hline
\end{tabular}

IgE (Kallestad Laboraories, Chaska, MN) but not by preincubation with purified preparations of human $\operatorname{IgA}, \operatorname{IgG}$, or human immunoglobulin light chains. The specificity of the detected IgE for parainfluenza virus antigen was also confirmed in control experiments in which positive reactions could be blocked by preincubating samples of secretions with PV-infected tissue culture cells followed by centrifugation, but not by preincubation with uninfected cells. Infants with infection due to other viral agents do not develop PV-IgE antibody (4).

Preparation of $P V$ antigen. PV antigen for use in the LTF assay was prepared by methods previously reported from this laboratory for preparation of other viral agents (10). Stock PV types 1 to 3 were grown in LLC-MK2 tissue culture cells to a concentration of $10^{6} \mathrm{TCID}_{50} / \mathrm{ml}$. The virus was partially purified by ultrasonification followed by centrifugation and was inactivated by ultraviolet irradiation. A control antigen was prepared by identical processing of uninfected LLC-MK2 cells.

$L T F$ responses. LTF responses to PV and to phytohemagglutinin were determined using a whole blood microculture technique previously utilized in this laboratory to determine LTF responses to other viral agents (10). Wells in microtiter trays were inoculated with whole blood diluted in RPMI growth medium with $10 \%$ fetal calf serum and $2 \mathrm{mM}$ glutamine. Dilutions were sufficient to permit inoculation with $2 \times 10^{5}$ lymphocytes per well. Triplicate cultures were stimulated with $20 \mu \mathrm{l}$ of PV antigen types 1, 2, or 3 or tissue control antigen each diluted $1: 4$ and $1: 16$ or else PHA or growth medium alone. Cultures were maintained for 5 and 6 days before pulsing with tritiated thymidine (New England Nuclear, Brookline, MA), harvesting, and assaying for radioactivity in a scintillation counter. Results are expressed both as stimulation index, or the ratio of $\mathrm{cpm}$ in PV antigen-stimulated to control antigen-stimulated cultures, or as $\Delta \mathrm{cpm}$, the difference in cpm between PV antigen and control antigen-stimulated cultures. LTF responses presented in the "Results" section and in the tables and Figure 1 represent the maximum response (considering each antigen dilution on day 5 or 6 of culture) induced by the PV antigen type corresponding to that of the PV strain causing the infection originally.

The specificity of the LTF assay for PV was determined in a preliminary study of another group of subjects followed prospectively and at the time of infection with viral agents other than PV. Results of these assays are shown in Table 1. In all cases, LTF responses showed a stimulation index of $<2.0$, and a change in counts per minutes of less than 100 .

Histamine-induced suppression of lymphoproliferation. Assays for the degree of suppression of LTF responses induced by the addition of histamine to cultures were performed by carrying out the above LTF assays in triplicate in the presence of histamine

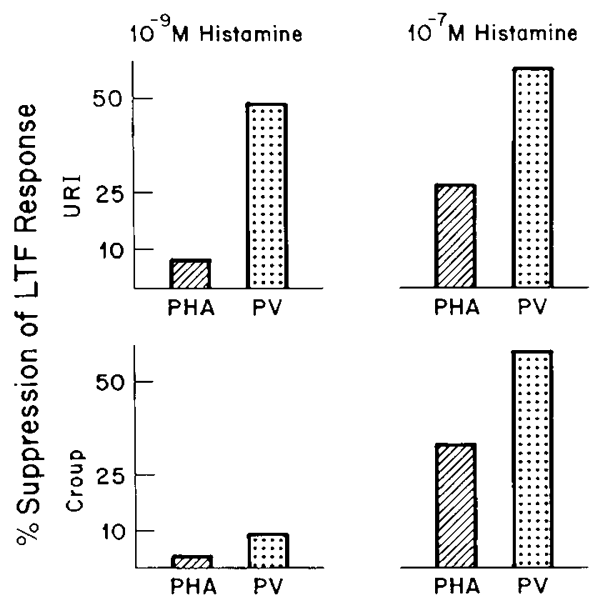

Fig. 1. Percentage suppression induced by histamine of LTF response to PV antigen and to PHA among patients with croup or URI alone due to PV. 
at a final concentration of $10^{-9}$ or $10^{-7} \mathrm{M}$, or an equal volume of buffer. The degree of histamine-induced suppression was calculated using the following equation:

$\%$ suppression $=\frac{\Delta \mathrm{cpm} \text { with buffer }-\Delta \mathrm{cpm} \text { with histamine }}{\Delta \mathrm{cpm} \text { with buffer }}$

Viability of cells (primarily $\mathrm{T}$ lymphocytes) at the end of the culture period was not influenced by the concentration of histamine ( $>95 \%$ viability by trypan blue exclusion).

LTF responses of low magnitude cannot be used reasonably to determine histamine-induced suppression, in that slight variances in cpm result in exaggerated percentages of suppression. Therefore only peak LTF responses obtained at the follow-up visit in which the SI was $\geq 2.0$ and the $\Delta \mathrm{cpm}$ was in excess of 100 were used to calculate degrees of suppression. In all, seven of 10 patients with URI alone and all 27 patients with croup met these criteria for inclusion. Therefore data for 34 of the 37 study patients $(92 \%)$ were included for analysis. The only criterion for exclusion of the three patients was inability to interpret the data because of lack of a meaningful immune response.

Statistical analysis. Differences between patient groups in terms of PV-IgE responses, lymphoproliferative responses, and degrees of suppression induced by histamine were compared using Student's $t$ test after logarithmic transformation of data. Correlation coefficients were calculated by the method of least squares.

\section{RESULTS}

PV-IgE responses analyzed by form of illness. Maximum PVIgE responses determined against the PV type causing infection are shown in Table 2. In all cases, maximum PV-IgE responses were obtained in the convalescent sample, or else the PV-IgE titers were identical in the acute and convalescent samples. The geometric mean titer \pm SD for patients with croup was $5.4 \pm$ 1.9 , while that for patients with URI alone was $1.5 \pm 2.5$, a difference which was statistically significant $(p<0.02)$. The overall kinetics of PV-IgE formation in similar patients have been reported previously (4). In 14 patients (data not shown) the titer of PV-IgE detected against PV types 1 and 3 was identical and, in 12 patients, the difference in titer was 2-fold. In three cases the difference in titer was 4-fold, and eight patients had no PV-IgE response. Despite the fact that no infections due to PV type 2 were documented, antibody to PV type 2 was frequently present in secretions. In almost all cases, PV-IgE titers against PV type 2 were 2-fold less than the maximum titer detected against $\mathrm{PV}$ types 1 or 3.

Maximum LTF responses to PV antigen analyzed by form of illness. LTF responses to PV antigen among patients in the two illness groups are shown in Table 3 . As previously noted, the LTF responses shown are those induced by PV antigen of the same type as the PV strain which caused infection. As explained in "Materials and Methods," appropriate samples were obtained only at the time of the follow-up visit. Results for all 37 patients are included, regardless of the magnitude of the LTF response. As indicated in Table 3, only seven of 10 patients with URI

Table 2. Peak PV-specific IgE titers in nasopharyngeal secretions

\begin{tabular}{|c|c|c|c|}
\hline $\begin{array}{l}\text { Illness } \\
\text { group }\end{array}$ & $\begin{array}{c}\text { No. } \\
\text { studied }\end{array}$ & $\begin{array}{c}\text { Peak PV-IgE titer* } \\
\text { (geometric mean } \\
\pm \mathrm{SD} \text { ) }\end{array}$ & \\
\hline URI & 10 & $1.5 \pm 2.5$ & \multirow{2}{*}{$\mathrm{p}<0.02$} \\
\hline Croup & 27 & $5.4 \pm 1.9$ & \\
\hline
\end{tabular}

* Titers corrected to protein content of $1 \mathrm{mg} / \mathrm{ml}$ fluid. Peak represents the maximum titer attained against the PV type causing infection in each patient. Student's $t$ test used for statistical comparison.
Table 3. LTF response to PV antigen analyzed by form of illness

Maximum LTF response $\dagger$

\begin{tabular}{lccc} 
& & \multicolumn{2}{c}{ Maximum LTF response $\dagger$} \\
\cline { 3 - 4 } $\begin{array}{c}\text { Form } \\
\text { of }\end{array}$ & $\begin{array}{c}\text { No. positive* } \\
\text { illness }\end{array}$ & $\begin{array}{c}\text { Stimulation } \\
\text { index }\end{array}$ & $\Delta$ no. tested \\
(geometric mean \pm SD) & (geometric mean \pm SD) \\
\hline URI & $7 / 10$ & $2.6 \pm 1.7$ & $81.3 \pm 42.7$ \\
Croup & $27 / 27$ & $4.1 \pm 1.7$ & $239.9 \pm 28.8$ \\
$p$ value & & $<0.01$ & $<0.05$ \\
\hline
\end{tabular}

* Stimulation index $\geq 2.0$.

$\dagger$ Maximum response induced by PV type corresponding to that of PV strain causing infection. Student's $t$ test used for statistical comparisons.

Table 4. Correlation of peak PV-specific IgE response with maximum $L T F$ response to $P V$ antigen

\begin{tabular}{ccc}
$\begin{array}{c}\text { Maximum PV- } \\
\text { IgE } \\
\text { titer in secretions }\end{array}$ & $\begin{array}{c}\text { Group geometric mean } \\
(\Delta \text { cpm } \pm \text { SE })\end{array}$ & \\
\hline Negative* & $93.3 \pm 3.0$ & $p=0.05$ \\
$1-4$ & $147.9 \pm 2.6$ & $p<0.025$ \\
$>4$ & $346.7 \pm 3.2$ & \\
\hline
\end{tabular}

* Undetectable with undiluted specimen. Student's $t$ test used for statistical comparison.

alone due to PV deveoped an LTF response of sufficient magnitude such that the stimulated index exceeded 2.0 , while stimulation indices for all 27 croup patients exceeded 2.0. When comparing the maximum LTF responses among all patients in the two illness groups, statistically significantly greater responses were observed among patients with croup whether the LTF response was expressed as stimulation index $(4.1 \pm 1.7$ versus $2.6 \pm 1.7, p<0.01)$ or as geometric mean $\Delta$ cpm $(239.9 \pm 28.8$ versus $81.3 \pm 42.7, p<0.05$ ). Differences in LTF responses to PHA were not significantly different for the two illness group ( $p$ $>0.40$, data not shown).

Cross-reactivity was observed when studying LTF responses to PV type 1 and type 3 antigens, in that positive responses to either antigen were usually observed regardless of which PV type caused the actual infection.

Relationship of maximum LTF response to PV antigen to peak $P V$-IgE response. The correlation of maximum LTF response to $\mathrm{PV}$ antigen with maximum PV-IgE response in all study patients is described in Table 4. Both the maximum LTF responses and PV-IgE responses analyzed in Table 4 are those specific to the infecting PV type. Patients were subdivided by the magnitude of PV-IgE antibody response in NPS into three groups: Those remaining negative for PV-IgE, those whose titer (when standardized by the amount of protein present) was between 1 and 4 , and those whose corrected titer was greater than 4 . An overall trend toward increased LTF responses to PV with increasing titer of PV-IgE produced was observed. Statistically significant differences were observed when comparing the PV-LTF response in the intermediate titer (PV-IgE titer of 1 to 4 ) group to that of the group with no PV-IgE response $(p=0.05)$ and when comparing the high titer group to the group with no response $(p<0.025)$. The coefficient of correlation of peak PV-IgE titers and maximum LTF responses to PV did not attain statistical significance $(r=0.286, p>0.10)$ suggesting that the correlation was nonlinear.

Histamine-induced suppression of LTF responses. The degree of histamine-induced suppression of LTF response to PV antigen and to PHA for patients with different forms of illness is shown in Figure 1. Data are included only from those patients whose LTF response to $\mathrm{PV}$ in convalescence was of sufficient magnitude so that the stimulation index was $\geq 2.0$ and the $\triangle \mathrm{cpm}$ exceeded 100 ( $92 \%$ of patients, see "Materials and Methods"). Increasing 
the final concentration of histamine in respective cultures from $10^{-9}$ to $10^{-7} \mathrm{M}$ resulted in increased suppression of the LTF response to both PV antigen and to PHA in all patients. The percentage suppression of the LTF response to PHA at each concentration of histamine was similar for patients in each illness group. Thus the percentage suppression at $10^{-9} \mathrm{M}$ histamine (geometric mean $\pm \mathrm{SD}$ ) was $6.9 \pm 9$ for URI patients and $2.6 \pm$ 10 for croup patients $(p>0.25)$, and at $10^{-7} \mathrm{M}$ histamine was $26.9 \pm 4$ for URI patients and $33.1 \pm 2$ for croup patients $(p>$ 0.25 ). In contrast, croup patients demonstrated significantly less histamine-induced suppression of the LTF response to PV at $10^{-9} \mathrm{M}$ histamine than URI patients. The percentage suppression for croup patients at $10^{-9} \mathrm{M}$ histamine was $9.3 \pm 4$ while for URI patients it was $49.0 \pm 11(p<0.01)$. Increasing the concentration of histamine to $10^{-7} \mathrm{M}$ resulted in equal suppression (approximately $58 \%$ ) in each illness group.

The correlation of individual values for percentage suppression of the LTF response to PV antigen at $10^{-9} \mathrm{M}$ histamine with peak individual PV-IgE titers was not statistically significant $(r$ $=0.089, p>0.25$ ).

\section{DISCUSSION}

The results of the present study identify several immunologic abnormalities in patients with croup due to PV. In contrast to patients with URI alone due to PV, croup patients manifest greater peak PV-IgE responses in NPS, increased LTF responses to PV antigen by peripheral blood lymphocytes, and reduced histamine-induced suppression of LTF responses to PV antigen. While it could be argued that some of these differences between the two illness groups could be accounted for by subjects in the two groups having a different number of exposures to PV, nevertheless the similar ages of subjects in the two groups suggest that the number of $\mathrm{PV}$ infections experienced was probably quite similar. While no data on the point were generated in the present study, other investigators have demonstrated that the histamineresponsive cell which initiates the suppressor mechanism is a Tlymphocyte which bears histamine type 2 receptors and the OKT-8 phenotype $(11,12)$. The most reasonable conclusion to be drawn might be that patients with croup manifest a deficiency in number and/or function of $T$ suppressor cells in comparison to normal individuals of the same age who develop only URI at the time of PV infection. The finding in the present study of an overall correlation of the magnitude of LTF responses to PV with the magnitude of PV-IgE responses suggests that the defect in suppression might rest in a single population of cells responsible for regulation of both lymphoproliferative responses as well as IgE production. While this is an attractive hypothesis, it has not been tested, and it should be noted that no significant correlation was observed in the present study between the degree of histamine-induced suppression of lymphoproliferative response to $\mathrm{PV}$ and the magnitude of the PV-IgE response. A significant negative correlation might have been expected if a single cell type were responsible for both functions. It is possible that a more complex relationship exists between regulation of lymphoproliferation and of $\operatorname{IgE}$ synthesis.

We believe that the differences in cell-mediated responses observed in the present study are due to true differences in immunoregulatory mechanisms, and not due to differences in severity of duration of illness, for several reasons. First patients with URI alone had prominent cough and rhinorrhea, often with fever, so the illnesses were not entirely trivial. Second, convalescent-phase samples were obtained after patients had been in good health for 1 to $2 \mathrm{wk}$, which would tend to minimize any effects of duration of illness. It has been demonstrated that non-IgE antibody responses to PV are similar among patients with URI alone or lower respiratory tract disease due to PV (3). Finally, the demonstration of reduced histamine-induced suppression of LTF responses in croup patients certainly suggests that differences in lymphoproliferative responses between the two illness groups are related to deficiencies in suppressor cell function rather than to differences in severity of illness.

The results of the present study are strikingly similar to those of studies of the immune response to RSV in infants with bronchiolitis $(10,13,14)$. These latter studies demonstrated that patients with RSV bronchiolitis manifest increased LTF response to RSV antigen (10), increased production of RSV-IgE in NPS (13), and reduced histamine-inducible suppression of LTF response to RSV (14) in comparison to patients with URI alone due to RSV. As in the present report, in which LTF responses to PV were studied, patients with RSV bronchiolitis were found to have deficient suppression of LTF responses to viral antigen, while the capacity to suppress responses to mitogenic stimulation was equivalent to that of groups with URI alone. While the response to other antigens needs to be studied, these findings at least suggest that patients with bronchiolitis and croup may have virus-specific defects in regulation of certain immune functions. Further studies of this point are in progress. It should also be noted that atopic patients also manifest reduced suppression of lymphoproliferation in response to histamine when compared to nonatopics $(15,16)$. The relationship of croup, particularly recurrent croup, to asthma has been the subject of several previous reports (17-19). Recurrent croup appears to occur more frequently among individuals with asthma and with family histories of asthma $(17,18)$ while children with croup at an early age frequently manifest wheezing at later ages $(18,19)$. Also children with croup can be shown to have airway hyperreactivity (19) which may persist for many years (20). The results of the present study provide an immunologic basis for a proposed link between croup, bronchiolitis, and atopic diseases.

Since it is known that lymphocytes stimulated by mitogens and a variety of antigens release soluble factors capable of enhancing basophil histamine release $(21,22)$ it is possible to interpret the results of the present study in the following manner. Lymphocytes of individuals with PV infection begin to proliferate, producing histamine-releasing factors that promote basophil histamine release as a physiologic mechanism of immune regulation. Proliferating lymphocytes of individuals prone to croup do not suppress adequately in response to the histamine signal, therefore continuing to produce releasing factors. As the level of free histamine increases, individuals, whose airways are hyperreactive to histamine may develop stridor or wheezing. Again, further testing of this hypothesis is required.

There is, to our knowledge, no information currently available concerning histamine levels in plasma or, more importantly, in the respiratory tract in croup, so it is not possible to state whether in vivo concentrations of histamine approximate those used in suppression assays in the present report. In a previous study from this laboratory (4) subjects with croup had a geometric mean concentration of $2 \mathrm{ng} / \mathrm{ml}$ of histamine in NPS, or $1.8 \times 10^{-8} \mathrm{M}$, but these secretions were diluted up to $1: 5$ in the collection process. In any case, the measured values in NPS may not reflect histamine concentrations to which lymphocytes are exposed in the respiratory mucosa. Histamine concentrations of approximately $6 \times 10^{-8} \mathrm{M}$ have been measured in plasma of human asthmatic subjects following antigenic inhalation challenge (23). Also it is possible that histamine concentrations of $10^{-3} \mathrm{M}$ may be achieved in sensitized human bronchial tissue following subsequent antigenic challenge (24), but these values are only estimates.

The results of the present study suggest that defects in immunoregulation may play a significant role in the pathogenesis of croup. These defects are similar to those observed in atopic individuals. Successful desensitization therapy in atopic individuals is associated with the generation of cells which phenotypically and functionally appear to be suppressor cells $(25,26)$. It may be that repeated exposures to PV, either by natural infection or by vaccination, may enhance suppressor cell function and thereby possibly prevent the occurrence of croup. 


\section{REFERENCES}

1. Denny FW, Murphy TF, Clyde WA, Collier AM, Henderson FW 1983 Croup: an 11-year study in a pediatric practice. Pediatr 71:871-876

2. Hall CE, Brandt CD, Frothingham TE, Spigland I, Cooney MK, Fox JP 1971 The virus watch program: a continuing surveillance of viral infections in Metropolitan New York families. Am J Epidemiol 94:367-385

3. Welliver R, Wong DT, Choi TS, Ogra PL 1982 Natural history of parainfluenza virus infection in childhood. J Pediatr 101:180-187

4. Welliver RC, Wong DT, Middleton E, Sun M, McCarthy N, Ogra PL 1982 Role of parainfluenza virus-specific IgE in pathogenesis of croup and wheezing subsequent to infection. J Pediatr 101:889-896

5. Gollapudi SVS, Kind LS 1977 Inhibition of IgE production in mice by nonspecific suppressor $T$ cells. Int Arch Allergy Appl Immunol 53:395-401

6. Zuraw BL, Nonaka M, O'Hair C, Katz DH 1981 Human IgE antibody synthesis in vitro: stimulation of $\mathrm{IgE}$ responses by pokeweed mitogen and selective inhibition of such responses by human suppressive factor of allergy (SFA). J Immunol 127:1 169-1177

7. Buckley RH, Sampson HA, Fisher PM, Becker WG, Shirley LR 1982 Abnormalities in the regulation of human IgE synthesis. Ann Allergy 49:67-72

8. Thomas Y, Hucht R, Granjon D 1981 Histamine-iduced suppressor cells of lymphocyte mitogenic response. Cell Immunol 59:268-275

9. Wong DT, Welliver RC, Riddlesberger KR, Sun MS, Ogra PL 1982 Rapid diagnosis of parainfluenza virus infection in children. $J$ Clin Microbiol 16:164-167

10. Welliver RC, Kaul A, Ogra PL 1979 Cell-mediated immune response to respiratory syncytial virus infection: relationship to the development of reactive airway disease. J Pediatr 94:370-375

11. Rocklin RE, Beard J, Gupta S, Good RA, Melmon KL 1980 Characterization of the human blood lymphocytes that produce a histamine-induced suppressor factor (HSF). Cell Immunol 51:226-237

12. Damle NK, Gupta S 1981 Autologous mixed lymphocyte reaction in man. II Histamine-induced suppression of the autologous mixed lymphocyte reaction by $T$-cell subsets defined with monoclonal antibodies $\mathbf{J}$ Clin Immunol $1: 241-249$

13. Welliver RC, Wong DT, Sun M, Middleton E, Vaughan RS, Ogra PL. 198
The development of respiratory syncytial virus-specific IgE and the release of histamine in nasopharyngeal secretions after infection. $N$ Engl $J$ Med 305:841-846

14. Welliver RC, Kaul TN, Sun M, Ogra PL 1984 Defective regulation of immune responses in respiratory syncytial virus infection. J Immunol 133:1925-1930

15. Martinez JD, Santos J, Stechschulte DJ, Abdou NI 1979 Nonspecific suppressor cell function in atopic subjects. J Allergy Clin Immunol 64:485-490

16. Beer DJ, Osband ME, McCaffrey RP, Soter NA, Rocklin RE 1982 Abnormal histamine-induced suppressor-cell function in atopic subjects. $\mathrm{N}$ Engl $\mathrm{J}$ Med 306:454-458

17. Konig $P 1978$ The relationship between croup and asthma. Ann Allergy 41:227-231

18. Zach M, Erben A, Olinsky A 1981 Croup, recurrent croup, allergy, and airways hyper-reactivity. Arch Dis Child 56:336-341

19. Zach MS, Schnall RP, Landau LI 1980 Upper and lower airway hyperreactivity in recurrent croup. Am Rev Respir Dis 121:979-983

20. Gurwitz D, Corey M, Levison H 1980 Pulmonary function and bronchial reactivity in children after croup. Am Rev Respir Dis 122:95-99

21. Thueson DO, Speck LS, Lett-Brown MA, Grant JA 1979 Histamine-releasing activity (HRA). I. Production by mitogen- or antigen-stimulated human mononuclear cells. J Immunol 123:626-632

22. Bamzai AK, Kretschmer RR 1978 Enhancement of antigen-induced leukocyte histamine release by a mononuclear cell-derived factor. J Allergy Clin Immunol 62:137-142

23. Atkins PC, Valenzano M, Zweiman B 1982 Plasma concentrations of histamine measured by radioenzymatic assay: effects of histaminase incubations. $\mathrm{J}$ Allergy Clin Immunol 69:39-45

24. Adams GK, Lichtenstein L 1979 In vitro studies of antigen-induced bronchospasm: effect of antihistamine and SRS-A antagonist on response of sensitized guinea pig and human airways to antigen. J Immunol 122:555-562

25. Canonica GW, Mingari MC, Melioli G, Colombatti M, Moretta L 1979 Imbalances of $T$ cell subpopulations in patients with atopic diseases and effect of specific immunotherapy. J Immunol 123:2669-2672

26. Rocklin RE, Sheffer AL, Greineder DK, Melmon KL 1980 Generation of antigen-specific suppressor cells during allergy desensitization. N Engl J Med 302:1213-1219

\title{
Morphologic and Metabolic Development of Human Fetal Epiphyseal Chondrocytes in Primary Culture
}

\author{
ANTONIO CARRASCOSA, LAURA AUDİ, AND ANGEL BALLABRIGA \\ Children's Hospital of the Seguridad Social, Autonomous University of Barcelona, Paseo del Valle Hebron s/n, \\ 08035 Barcelona, Spain
}

\begin{abstract}
Primary chondrocyte culture was carried out after enzymatic digestion of femoral and tibial epiphyseal cartilage of human fetuses, collected with informed parental consent within $12 \mathrm{~h}$ postmortem. Chondrocytes were cultured in HAM F-12 medium with penicillin and $15 \%$ serum. Three types of serum were used: human placental cord serum (HPS), fetal calf serum, and human male adult serum. Chondrocytes cultured with HPS grew as monolayers, formed abundant colony groups with a highly metachromatic pericellular matrix, and floating round cells were observed in the culture medium. By the 10th day of culture

Received May 17, 1984; accepted February 27, 1985

Reprint requests Antonio Carrascosa, Clinica Infantil Valle Hebron, Paseo del Valle Hebron s/n, 08035 Barcelona, Spain.

Supported by Grant 301/81 from "Fondo de Investigaciones Sanitarias de la
\end{abstract} Seguridad Social," España. the great majority of proteoglycans present in the culture medium were found as aggregates. Chondrocytes cultured with fetal calf serum or human male adult serum grew as monolayers, were polygonal in shape, and the pericellular matrix was far less developed than in HPS cultures. By the confluent phase of growth, only approximately a third of the proteoglycans present in the culture medium were found as aggregates. Chondrocytes cultured with HPS proliferated significantly more rapidly than those cultured with fetal calf serum or human male adult serum. The results suggest that certain, as yet unidentified, factors are present in sufficient amount in HPS to allow chondrocytes in culture to retain phenotypic morphological and biochemical characteristics. HPS also facilitates growth of human fetal epiphyseal chondrocytes in culture. Primary human 